\title{
COMPORTAMENTO REPRODUTIVO DE SPOROPHILA LINEOLA (LINNAEUS) (PASSERIFORMES, EMBERIZIDAE)
}

\author{
Luiz Octavio Marcondes-Machado ${ }^{1}$
}

\begin{abstract}
RLPRODUCTIVL BEHAVIOR OF SPOROP'IIL LA LINEOL.4 (LINNALUS) (PASSERIFORMES, EMBERIZIDAE). This study on the biology and reproductive behavior of Sporophila lineola (Linnaeus, 1758) was carried in a Citrus reticulata Blanco plantation near Campinas, Brazil. A blind was used for observations near the four nests. These were built on the branches of $C$. reticulata, and were made of grass roots. The clutch varies from two to three eggs. Both male and female or only female, feed the nestings with insects such as dragonfly and caterpillar, carried across their bill.

KEY WORDS. Reproductive behavior, Sporophila, biology.
\end{abstract}

Sporophila lineola (Linnaeus, 1758), conhecida vulgarmente por bigodinho ou estrelinha (ANDRADE 1982) é encontrada nos descampados, plantações, beira de capoeiras (SICK 1985) e pomares (ANDRADE 1992). Ocorre das Guianas e Venezuela à Bolívia, Paraguai, Argentina e Brasil, até Paraná, Mato Grosso, Mato Grosso do Sul e Goiás (SiCK 1985; Ridgely \& TUdor 1989; DA Silva 1995). Apresenta hábitos migratórios, aparecendo do Espírito Santo ao Paraná, em dezembro para nidificar e migrando em março e abril (SICK 1985; DA SiLVA 1995).

Este trabalho teve por objetivo fornecer informações sobre a reprodução de S. lineola, como o local utilizado para construção de ninhos, interação entre macho e fêmea e cuidados à prole, em ambiente antrópico.

\section{MATERIAL E MÉTODOS}

Ao longo de dois meses (fevereiro e março de 1993) foram realizadas observações de quatro ninhos localizados em um pomar de Citrus reticulata Blanco, no sítio São Luis ( $22^{\circ} 48^{\prime} 11^{\prime \prime S}, 47^{\circ} 03^{\prime} 12^{\prime \prime} \mathrm{W}$, altitude $\left.700 \mathrm{~m}\right)$, no subdistrito de Barão Geraldo, município de Campinas, São Paulo.

Utilizou-se um abrigo de pano verde, que permitiu que as observações fossem realizadas de pequenas distâncias, com auxílio de binóculo (Asahi Pentax, $7 \times 50)$.

O estudo foi efetuado tanto no período da manhã (08:00-11:30h) como da tarde (16:00-18:00h) num total de 120 horas de observação, segundo o método de amostragem ad libitum (ALTMAN 1974), através do qual se registra todo o comportamento efetuado pelo casal.

1) Departamento de Zoologia, Instituto de Biologia, Universidade de Campinas. Caixa Postal 6109, 13083-970 Campinas, Säo Paulo, Brasil. 
Foi feita análise do intervalo médio de alimentação absoluto por indivíduo; e por casal ponderado por ninhego. A comparação entre as médias de intervalos de alimentação ponderados por ninhego foi feita por teste t de Student, entre os dois casais. Análise de variância unifatorial foi empregada na composição das médias de intervalos absoluto de alimentação entre os indivíduos estudados.

\section{RESULTADOS}

Os quatro ninhos estudados foram construídos em galhos de C. reticulata a diferentes alturas do solo, estes dados e as medidas dos ninhos são apresentados na tabela I. Os ninhos tinham forma de tigela e eram constituídos de raízes de gramíneas, possivelmente de capim colonião (Panicum maximum Jacq.), formando uma trama rala (Fig. 1). Em um deles havia um fio de nylon azul claro do tipo utilizado em pescaria. Foi observado apenas uma postura por ninho.

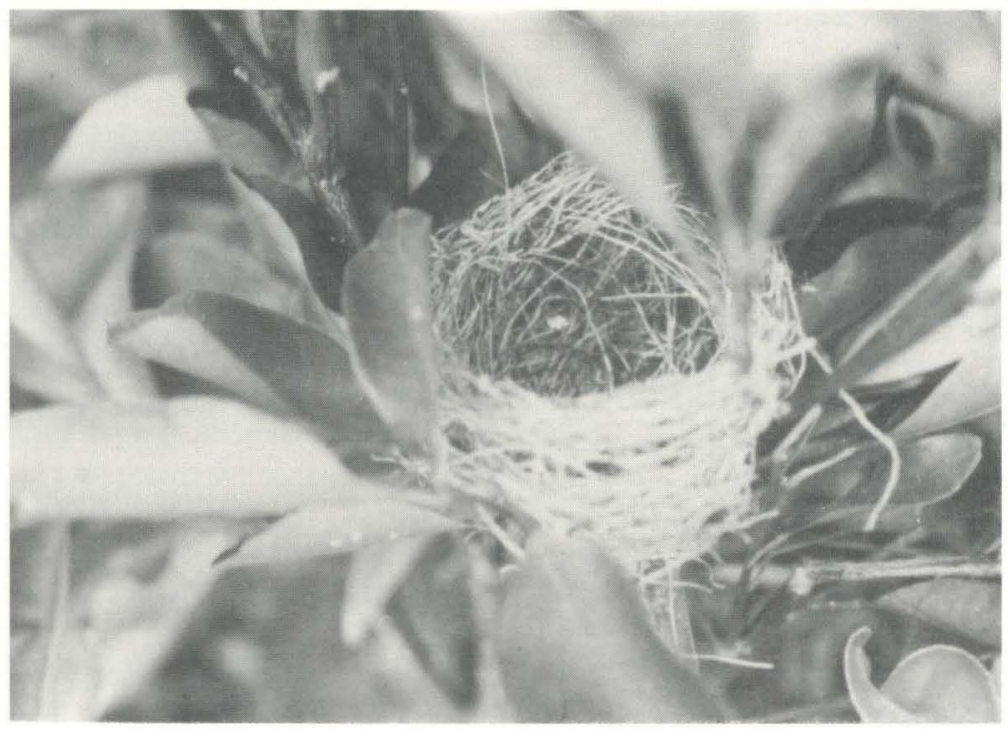

Fig. 1. Ninho de Sporophila lineola construido em galhos de Citrus reticulata.

Tabela I. Medidas de quatro ninhos encontrados em um pomar de Citrus reticulata.

\begin{tabular}{ccccc}
\hline Ninho & $\begin{array}{c}\text { Altura do solo } \\
(\mathrm{cm})\end{array}$ & $\begin{array}{r}\text { Diâmetro interno } \\
(\mathrm{cm})\end{array}$ & $\begin{array}{r}\text { Diâmetro externo } \\
(\mathrm{cm})\end{array}$ & $\begin{array}{c}\text { Profundidade } \\
(\mathrm{cm})\end{array}$ \\
\hline 1 & 3,23 & 5,00 & 5,65 & 3,70 \\
2 & 4,20 & 5,17 & 6,12 & 2,82 \\
3 & 2,65 & 5,04 & 6,08 & 3,00 \\
4 & 3,15 & 5,00 & 5,74 & 4,15 \\
Médias & 3,30 & 5,05 & 5,89 & 3,44 \\
\hline
\end{tabular}


Todos os ninhos, ao serem encontrados, estavam na fase de desenvolvimento dos ninhegos, sendo que em um deles os ninhegos eram recém-nascidos. O número de ninhegos por ninho variou de $2(n=3)$ a $3(n=1)$ e todos eles completaram seu desenvolvimento e deixaram os respectivos ninhos.

Somente as fêmeas incubaram. Devido a sua coloração parda clara semelhante ao material do ninho, elas se mostraram pouco visíveis. Os machos ficaram nas proximidades dos ninhos cantando. Atendem ao play-back com gravação do canto da espécie, embora os ninhos tenham sido construídos a pouca distância um do outro. O ninho 1 e o ninho 2 tinham ninhegos simultaneamente e distavam entre si $60 \mathrm{~m}$. Os ninhegos do ninho 2 estavam ainda implumes, quando os ninhegos do ninho 1 deixaram o ninho. Foi encontrado o ninho 3 a $15 \mathrm{~m}$ do ninho 2 e com filhotes da mesma idade deste.

Nos ninhos com dois ninhegos, apenas as fêmeas alimentavam-nos, enquanto os machos cantavam nas proximidades, já no único ninho observado com três ninhegos, tanto o macho como a fêmea os alimentavam. Os valores médios do tempo interalimentação, o erro-padrão, a amplitude de variação e o tamanho amostral utilizados na comparação da frequência de alimentação de uma fêmea sozinha com dois ninhegos e de um casal alimentando três ninhegos estão apresentados na tabela II. O resultado da ANOVA unifatorial não revelou diferença significativa entre os três indivíduos (ANOVA $\mathrm{F}_{12}=0,435, \mathrm{p}=0,66, \mathrm{NS}$ ). Utilizando os dados da tabela III, foi feito teste t comparando as médias do tempo entre alimentação dos casais. Não houve diferença significativa entre elas $\left(t_{8}=2,304, p=0,096, N S\right)$.

Tabela II. Médias em segundos ( \pm erro padrão) do tempo entre alimentação para dois ninhos atendidos diferenciadamente por uma fêmea ou um casal.

\begin{tabular}{lccc}
\hline & $\begin{array}{c}\text { Fêmea só } \\
(2 \text { ninhegos })\end{array}$ & $\begin{array}{c}\text { Macho casal } \\
\text { (3 ninhegos) }\end{array}$ & $\begin{array}{c}\text { Fêmea casal } \\
\text { (3 ninhegos) }\end{array}$ \\
\hline Média & 386,25 & 581,25 & 501,25 \\
Erro padrão & 32,99 & 215,28 & 137,01 \\
Amplitude mínima & 327,00 & 276,00 & 276,00 \\
Amplitude máxima & 480,00 & 1200,00 & 900,00 \\
$\mathrm{~N}$ & 4 & 4 & 4 \\
\hline
\end{tabular}

Tabela III. Médias em segundos ( \pm erro padrão) do tempo de alimentação nos dois casais estudados.

\begin{tabular}{lcc}
\hline & Casal 1 & Casal 2 \\
\hline Média & 193,125 & 360,825 \\
Erro padrão & 16,493 & 70,893 \\
Amplitude mínima & 163,500 & 192,000 \\
Amplitude máxima & 240,000 & 533,000 \\
$\mathrm{~N}$ & 4 & 4 \\
\hline
\end{tabular}


Quando era a fêmea que alimentava sozinha os ninhegos, ela dividia o tempo de atenção à prole, entre ficar pousada sobre os ninhegos, abandonar o ninho à procura de alimento, indo até touceiras de capim colonião onde pousava em uma espiga, retirando os cariopses que descascava, ingerindo as sementes, alimentar os ninhegos e promover a higiene do ninho.

Quando voltava ao ninho pousava em um galho próximo, emitia um piado e então pousava na borda do ninho e alimentava os ninhegos. Após a alimentação, a fêmea permanecia neste local e se havia bolo fecal, apreendia-o com o bico e se afastava com ele, voltando alguns minutos mais tarde, alimentando novamente os ninhegos, pousando em seguida sobre eles. Na maior parte das vezes regurgitava o alimento na garganta dos dois ninhegos, mas algumas vezes trazia insetos presos no bico, como pequenas lagartas (Lepidoptera) e libélulas (Odonata), que eram introduzidas pela cabeça e por inteiro na garganta dos ninhegos. Pode também forragear por entre as folhas de Citrus, capturando pulgões, que vão engolindo, indo após alimentar os ninhegos. Estes quando eram alimentados piavam com o bico aberto e o pescoço esticado. Adotavam esta postura apenas quando a fêmea estava com seu bico apontado para eles.

No ninho com três ninhegos, tanto o macho como a fêmea cuidavam da alimentação, como também da retirada dos sacos fecais do interior do ninho, até quando estavam já empenados e prestes a deixá-lo.

Os ninhegos permaneceram no ninho por cerca de nove dias $(n=1)$.

\section{DISCUSSÃO E CONCLUSÕES}

As espécies e subespécies do gênero Sporophila constroem o ninho em forma de tigela aberta, rala (ARMANI 1983; SICK 1985). Segundo DE LA PEÑA (1981) que observou um ninho de $S$. lineola, este possui a forma de tigela construída com raizes em um arbusto. O local de construção em árvores ou arbustos também foi utilizado por S. americana aurita (Bonaparte, 1851) (Gross 1952; SKUTCH 1954) e $S$. nigricollis (Vieillot, 1823) (ALDERTON 1961; FFRENCH 1965), pertencentes ao mesmo gênero.

O material utilizado para a construção do ninho de $S$. caerulescens (Vieillot, 1823) (IHERING 1900) e S. torqueola (Bonaparte, 1851) (SKUTCH 1954), também são raízes de capim, como o encontrado para $S$. lineola, evidenciando uma tendência na utilização deste material para a feitura do ninho.

Assim como na espécie em estudo, os machos de $S$. nigricollis e $S$. albogularis (Spix, 1825) também cantam próximos ao local do ninho (ALDERTON 1961; MARCONDES-MACHADO 1982).

As medidas do ninho de $S$. lineola não diferem muito daquelas obtidas para outras espécies do mesmo gênero. O ninho de $S$. albogularis tem $4,8 \mathrm{~cm}$ de diâmetro interno e 3,8cm de profundidade (MARCONDES-MACHADO 1982); o de S. nigricollis tem $5,0 \mathrm{~cm}$ de diâmetro interno por $4,3 \mathrm{~cm}$ de profundidade, construído a uma altura máxima do solo de $3 \mathrm{~m}$ e mínima de 1,70m (ALDERTON 1961) e o de $S$. caerulescens mede $5,0 \mathrm{~cm}$ de diâmetro interno por 4,0 cm de profundidade (EULER 1900). O ninho de $S$. lineola observado por DE LA PEÑA (1981) tinha $4 \mathrm{~cm}$ de diâmetro e $3 \mathrm{~cm}$ de profundidade, construido a $2,50 \mathrm{~m}$ do solo (Tab. IV). 
Tabela IV. Medidas referentes a ninhos de diferentes espécies de Sporophila citadas na literatura.

\begin{tabular}{lccc}
\hline \multicolumn{1}{c}{ Espécie } & $\begin{array}{c}\text { Diâmetro interno } \\
(\mathrm{cm})\end{array}$ & $\begin{array}{c}\text { Diâmetro externo } \\
(\mathrm{cm})\end{array}$ & $\begin{array}{c}\text { Altura do solo } \\
(\mathrm{m})\end{array}$ \\
\hline Sporophila albogularis & 4,8 & 3,8 & - \\
Sporophila nigricollis & 5,0 & 4,3 & $3,00-1,70$ \\
Sporophila caerulescens & 5,0 & 4,0 & - \\
Sporophila lineola & 4,0 & 3,0 & 2,50 \\
\hline
\end{tabular}

Como o ninho é moldado pelo corpo do pássaro e as espécies pertencentes ao gênero Sporophila citadas acima possuem comprimento de cerca de $11 \mathrm{~cm}$, era de se esperar portanto, que seus ninhos tivessem dimensões semelhantes.

Tanto S. albogularis (MARCONDES-MACHADO 1982) como S. nigricollis (ALDERTON 1961) constroem ninhos consecutivos, após a saída dos ninhegos, como em S. lineola. Tanto este comportamento como o de eliminar os sacos fecais, provavelmente previnem o aumento de ectoparasitas.

Segundo SKUTCH (1954), posturas compostas de dois ovos parecem ser a regra entre as espécies tropicais de Sporophila. Em S. americana corvina (Sclater, 1859 ) e $S$. torqueola foram encontrados três ovos em algumas posturas como em $S$. lineola. Para ARMANI (1983) a postura desta espécie é composta por dois a três ovos. Possivelmente o pequeno número de ovos encontrados nas espécies do gênero, seja devido a pouca proteção que o tipo de ninho em tigela oferece (LACK 1968).

A fềmea do casal 1 , que alimentou os dois ninhegos sozinha, os alimentou a intervalos de tempo semelhantes ao empregado pelo casal 2 para alimentar os três ninhegos.

Pela ANOVA unifatorial foi constatado não haver diferença significativa no intervalo absoluto de alimentação à prole.

A inclusão pelos pais de invertebrados na alimentação de ninhegos de espécies granívoras já foi observado por alguns autores como CARVALHO (1957), ALDERTON (1962), LACK (1968) e MARCONDES-MACHADO (1982). O exame do conteúdo estomacal de espécies da mesma família como S. plumbea (Wied, 1831), Oryzoborus angolensis (Linnaeus, 1766), e Volatinia jacarina (Linnaeus, 1766), de exemplares coletados nos meses de setembro e outubro, início da primavera e começo do período reprodutivo de muitas espécies de pássaros, embora para as três espécies aqui citadas não haja dados a respeito na literatura, evidenciou a existência de restos de insetos (SCHUBART et al. 1965). S. lineola inclui insetos na alimentação de seus ninhegos, regurgitando os pequenos como pulgões e trazendo no bico lagartas e libélulas, que introduzia inteiras na garganta do ninhego, procedendo assim de maneira diferente da citada por SICK (1985) para o gênero, quando afirma que os pais engolem o alimento para depois regurgitá-los parcialmente digerido na garganta do ninhego.

AGRADECIMENTOS. À Lidia Penteado Sandoval pela inestimável ajuda e apoio no campo. À Sandra Jammal Paranhos e à Sônia Buck pela amizade e ajuda na revisão e digitação do texto.

À Claudia Alves de Magalhães, pelo apoio estatístico. Ao CNPq pelo apoio. 


\section{REFERÊNCIAS BIBLIOGRÁFICAS}

Alderton, C.C. 1961. The breeding cycle of the yellow-bellied seedeater in Panamá. Condor 63: 390-398.

ALTMAN, J. 1974. Observational study of behavior methods. Behavior 49: 227-267.

Andrade, G.A. 1982. Nomes populares das aves do Brasil. Belo Horizonte, SOM/IBDF, 95p.

Andrade, M.A. 1992. Aves Silvestres: Minas Gerais. Belo Horizonte, CIPA, $176 \mathrm{p}$.

ARMANI, G.C. 1983. Guide des passereaux granivores. Paris, Delachaux et Niestlé, 262p.

Carvalho, C.T. 1957. Notas ecológicas sobre Volatinia jacarina (Passeres, Fringillidae). Bol. Mus. Para. Emilio Goeldi, N.S., Zoologia, 1 (2): 10.

DA Silva, J.M.C. 1995. Seazonal distribution of the Lined Seedeater Sporophila lineola. Bull. B.O.C. 155 (1): 14-21.

DE LA PEÑA, M. 1981. Notas nidobiológicas sobre corbatitas (Aves, Emberizidae). Segunda Parte. Hist. Nat. 2 (6): 45-48.

Euler, C. 1900. Descrição de ninhos e ovos das aves do Brasil. Revta Mus. Paul. 4: 9-148.

FFRENCH, R.P. 1965. The nesting behavior of yellow-bellied seedeater. Carib. Jour. Sci 5: 149-156.

Gross, A.D. 1952. Nesting of hick's seedeater at Barro Colorado Island, Canal Zone. Auk. 69: 433-446.

IHERING, H. VON. 1900. Catálogo crítico - comparativo dos ninhos e ovos das aves do Brasil. Revta Mus. Paul. 4: 191-300.

LACK, D. 1968. Ecological adaptations for breeding in birds. London, Methuen, 409p.

MARCONDES-MACHAdO, L.O. 1982. Notas sobre a reprodução de Sporophila albogularis (Spix, 1825) (Passeriformes, Emberizidae) em cativeiro. Iheringia, Sér. Zool. (61): 81-89.

Ridgely, R.S. \& G. Tudor. 1989. The birds of South America. Oxford, Oxford University Press, vol. 1, 516p.

SCHubart, O.; A.C. A Guirre \& H. Sick. 1965. Contribuição para o conhecimento da alimentação das aves brasileiras. Arq. Zool. Est. S. Paulo 12: 95-249.

SicK, H. 1985. Ornitologia brasileira, uma introdução. Brasília, Editora da Universidade de Brasília, 827p.

SKuTCH, A.F. 1954. Life histories of Central American birds. Berkeley, Cooper Ornitological Society, 449p.

Recebido em 19.VII.1996; aceito em 15.VIII.1997. 